\title{
Ethical climate and nurse competence - newly graduated nurses' perceptions
}

\section{Numminen, Olivia}

\author{
2015-12
}

Numminen , O , Leino-Kilpi , H , Isoaho , H \& Meretoja , R 2015 , ' Ethical climate and nurse competence - newly graduated nurses' perceptions ' , Nursing Ethics , vol. 22 , no. 8 , pp. 845-859 . https://doi.org/10.1177/0969733014557137

http://hdl.handle.net/10138/233397

https://doi.org/10.1177/0969733014557137

publishedVersion

Downloaded from Helda, University of Helsinki institutional repository.

This is an electronic reprint of the original article.

This reprint may differ from the original in pagination and typographic detail.

Please cite the original version. 


\title{
Ethical climate and nurse competence - newly graduated nurses' perceptions
}

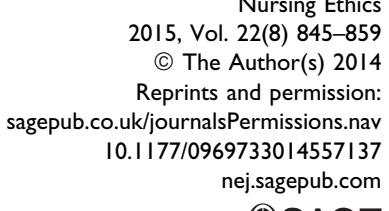

(SAGE

\section{Olivia Numminen}

Hospital District of Helsinki and Uusimaa, Finland

\author{
Helena Leino-Kilpi \\ University of Turku, Finland; Turku University Hospital, Finland
}

\section{Hannu Isoaho}

Statcon Ltd, Finland

Riitta Meretoja

Hospital District of Helsinki and Uusimaa, Finland; University of Turku, Finland

\begin{abstract}
Background: Nursing practice takes place in a social framework, in which environmental elements and interpersonal relations interact. Ethical climate of the work unit is an important element affecting nurses' professional and ethical practice. Nevertheless, whatever the environmental circumstances, nurses are expected to be professionally competent providing high-quality care ethically and clinically.

Aim: This study examined newly graduated nurses' perception of the ethical climate of their work environment and its association with their self-assessed professional competence, turnover intentions and job satisfaction.

Method: Descriptive, cross-sectional, correlational research design was applied. Participants consisted of 318 newly graduated nurses. Data were collected electronically and analysed statistically.

Ethical considerations: Ethical approval and permissions to use instruments and conduct the study were obtained according to required procedures. Data were rendered anonymous to protect participant confidentiality. Completing the questionnaire was interpreted as consent to participate.

Findings: Nurses' overall perception of the ethical climate was positive. More positive perceptions related to peers, patients and physicians, and less positive to hospitals and managers. Strong associations were found between perceived ethical climate and self-assessed competence, turnover intentions in terms of changing job, and job satisfaction in terms of quality of care. Nurses at a higher competence level with positive views of job satisfaction and low turnover intentions perceived the climate significantly more positively.

Conclusion: Nursing management responsible for and having the power to implement changes should understand their contribution in ethical leadership, as well as the multidimensional nature of nurses' work environment and the interaction between work-related factors in planning developmental measures. Future research should focus on issues in nurse managers' ethical leadership in creating ethical work environments.
\end{abstract}

Corresponding author: Olivia Numminen, Hospital District of Helsinki and Uusimaa, Corporate Headquarters, Box I00, FI-00029 Helsinki, Finland.

Email: j.o.numminen@welho.com 
There is also a need for knowledge of newly graduated nurses' views of factors which act as enhancers or barriers to positive ethical climates to develop. Interventions, continuing education courses, and discussions designed to promote positive ethical climates should be developed for managers, nurses, and multi-professional teams.

\section{Keywords}

Ethical climate, job satisfaction, multivariate study, newly graduated nurse, self-assessed professional competence, turnover intentions, workforce

\section{Introduction}

Nursing practice takes place in a social framework, in which environmental elements and interpersonal relations interact. Thus, when nurses encounter ethical issues in their daily practice, it is not happening only in caring for their patients but also in relation to colleagues, other healthcare professionals, the employing organization and the society. ${ }^{1}$ Climate of the work unit is an important element affecting nurses' behaviour and practice. ${ }^{2}$ Nevertheless, whatever the environmental circumstances, nurses are expected to be professionally competent providing high-quality care both ethically and clinically. For such care, an environment supporting ethical practice is a prerequisite. ${ }^{3}$ As a part of organizational climate, ethical climate affects the individual nurse by constraining, rewarding or punishing her or his behaviour. It affects the development of the nurse's moral agency and identity and has, for example, repercussions to the nurse's willingness to show moral courage in issues that have ethical implications. ${ }^{4,5}$ The influence of ethical climate occurs on one hand through formal culture, which includes leadership, structure, policies, reward systems, socialization mechanisms and decision-making processes, and on the other hand through informal culture, manifesting in behavioural norms, role models, rituals, historical anecdotes and

language. ${ }^{6-8}$ Given that ethical climate is associated with ethical behaviour, it should be taken into account in assessing nurses' behaviour. Ethical climate has also been recognized as an important factor in explaining nurses' turnover intentions and job satisfaction. ${ }^{9,10}$ In pursuing ethically and clinically high-quality care, modern healthcare systems, struggling with issues of nurses' turnover, job satisfaction and nurse competence, including its intelligent targeting, should take into account the association of ethical climate with these issues. ${ }^{11,12}$

Particular interest focuses on newly graduated nurses, whose feelings of uncertainty and whose experiences of factors shaping their work environment during the early years of their career are known to have either a positive or an adverse impact on their commitment to nursing profession and on their further professional development. ${ }^{13-16}$ It is also important to realize that the ethical knowledge base provided by basic nursing education is but a starting point to newly graduated nurses' further professional ethical development in practice. ${ }^{17}$ Thus, the ethical climate may have a positive or negative influence also on newly graduated nurses' ethical and professional competence development, job satisfaction and retaining them in nursing.

The purpose of this study was to explore newly graduated nurses' perceptions of the ethical climate of their work environment and its associations with their self-assessed professional competence, turnover intentions and job satisfaction.

\section{Background}

\section{Ethical climate}

Ethical climate is defined as a shared perception of what ethically acceptable behaviour is, and how ethical issues are addressed within an organization. Ethical climate reflects the organization's policies, procedures and practices in relation to moral issues, and their influence on the ethical beliefs and behaviours of the 
employees. ${ }^{6,18,19}$ In healthcare, ethical climate reflects organizational practices and values in care issues with ethical connotations and how these issues are discussed and resolved ${ }^{20,21}$ referring to difficult patient care issues as well as interactions and relationships that nurses have with their colleagues, other healthcare professionals, the employing organization and the society. ${ }^{1}$ In short, in nursing, ethical climate has been described as the nurses' perceptions of handling ethical issues in their work setting. ${ }^{22}$

Literature describes different types of ethical climates and theories behind them. An introductory theory of ethical climate developed by Victor and Cullen ${ }^{18}$ and the Ethical Climate Questionnaire ${ }^{21}$ based on their theory is well known and widely used to measure ethical climates in different organizational contexts. The instrument recognizes nine different ethical climate types. ${ }^{18,19}$ Other instruments to measure ethical climates have since been developed for business, education and service settings. ${ }^{23,24}$ Olson $^{6,22}$ realized the lack of an instrument measuring ethical climate particularly in healthcare organizations and developed the Hospital Ethical Climate Survey (HECS) to measure nurses' perceptions of ethical climate in hospital work environment in five central dimensions, that is, in relation to peers, patients, managers, hospitals and physicians. This study focused on nurses' perceptions of the ethical climate; hence, HECS was considered the most suitable instrument.

Ethical climate and its association with work-related factors have been the focus of interest in various studies dealing with healthcare organizations. ${ }^{8,25,26}$ These studies have approached ethical climate from the perspectives of a hospital, hospital administration and work units, as well as managers, physicians, nurses and patients.

In nursing, studies have focused on nurses' perceptions of the ethical climate of their work environment, ${ }^{27}$ and its association with nurses' turnover intentions, or leaving the profession, ${ }^{9,21}$ job satisfaction and organizational commitment. ${ }^{28-30}$ Types of ethical climates in different nursing environments ${ }^{8,26,29,30}$ and factors promoting positive ethical climates have also been in focus. ${ }^{20,23,31-34}$ Some studies have dealt with nurses' socio-demographic factors and their association with ethical climate ${ }^{27}$ and ethical climate's relation to moral distress. ${ }^{13,35-37}$ However, ethical climate's association with nurses' professional competence as a pivotal factor in provision of high-quality care has not been addressed in nursing research.

In several earlier studies, nurses' overall perception of the ethical climate has mainly been positive. ${ }^{27,35,37,38}$ However, since clinical context plays a part in shaping nurses' ethical practice and experience, ${ }^{4}$ clinical context has a potential to induce negative perceptions as well. According to Varcoe et al., ${ }^{5}$ forces acting in clinical context constrained nurses' ability to be and act as moral agents. Nurses felt that they had to work in between their own values and values of the organization, in between their own values and values of others, and in between competing values and interests which manifested as a professional and personal struggle in sustaining the identity of a moral agent in doing what was seen as good.

Positive perceptions of ethical climate have associations with many work-related factors. Positive climate contributed to nurses' intentions to stay in their jobs and in the profession. ${ }^{9,38}$ Extensive institutional support in dealing with ethical issues protected nurses from leaving their current jobs. ${ }^{39}$ Moreover, ethical climates fostering caring and well-being of others had a positive influence on nurses' job satisfaction, whereas climates fostering instrumental approach and ethical decision-making based on personal moral convictions had a negative impact on perceptions of ethical climate. ${ }^{29,30}$ Supportive hospital management enhanced positive ethical climates. ${ }^{20,27,30-33}$ Positive ethical climate was enhanced by managers' actions in which focus was on patients, ${ }^{27}$ as well as on shared responsibility and teamwork with commitment to ethical behaviour. ${ }^{33}$ Inter-professional cooperation and adequate communication were also needed. ${ }^{25}$

Lack of commitment to the hospital's mission and physicians not consulting nurses about care created negative climates. ${ }^{27}$ Instead, nurses felt themselves silenced due to hierarchic professional cultures. ${ }^{40}$ Hartrick Doane $^{4}$ and Varcoe et al. ${ }^{5}$ found that contextual and organizational factors, for example, ethical climates highlighting privileged position of biomedicine, corporate efficiency and scarce resources, affected nurses' moral identity and moral agency resulting in uncertainty and need to compromise in ethical decisions. 
Ethical climates also differed between healthcare organizations. ${ }^{8,28}$ Climates were not static but changed with changes in leadership styles and organizational practices. ${ }^{29}$ Also type of hospital and work unit influenced perceptions of ethical climate in that nurses in private hospitals, and in paediatric and intensive care units, perceived ethical climate more positively than nurses in other hospitals and units. ${ }^{27}$

Of socio-demographic factors, education and work experience did not seem to have much influence on nurses' positive perceptions of the climate, in that young and inexperienced nurses perceived ethical climate more positively than older and more experienced nurses. ${ }^{27}$ Although positive perception of ethical climate correlated positively with low experience of moral distress, ${ }^{13,35-37}$ Schluter et al. ${ }^{21}$ concluded that there is not enough evidence to support the claim that ethical climate and moral distress have impact on nurse turnover.

\section{Professional competence and other work-related factors}

The concept of professional competence refers to the nurse's capability to act and her capacity to integrate knowledge, skills, attitudes and values in a certain contextual nursing situation. ${ }^{41,42}$ The Nurse Competence Scale $\left(\mathrm{NCS}^{41}\right)$ used in this study to measure nurses' self-assessed competence has been developed on this definition of the concept. Nurse turnover refers to the individual's perception about the possibility of voluntarily leaving the present job. ${ }^{43}$ It has been described as a withdrawal process of consecutive phases leading finally to leaving the profession. ${ }^{44,45}$ Job satisfaction refers to the extent to which employees like their jobs and can be conceptualized as a related cluster of attitudes of different aspects of the job. ${ }^{46}$

Newly graduated nurses' professional competence has been addressed in a few studies. ${ }^{47,48}$ Studies have indicated that competence is associated with newly graduated nurses' turnover intentions and job satisfaction. ${ }^{49}$ Graduated nurses' willingness to change job or leave the nursing profession for good are acknowledged facts. ${ }^{11,12,50-52}$ Research on nurses' job satisfaction is extensive and numerous associated factors have been identified, for example, with nursing profession, job orientation and professional competence. ${ }^{11,30,53}$ Turnover intentions and job satisfaction have also been found to be interrelated.

In summary, ethical climate has been studied in relation to several work-related factors in nursing context, and there is evidence of its associations with nurses' work environment, turnover intentions, job satisfaction and competence. ${ }^{51,54,55}$ However, a gap in the literature still exists how these associations show particularly in relation to newly graduated nurses, therefore needing further exploring. Based on earlier research, it is hypothesized here that newly graduated nurses' perceptions of ethical climate as one element of nurses' work environment also have associations with their turnover intentions, job satisfaction and their self-assessed professional competence.

\section{The study}

\section{Purpose}

This study examined newly graduated nurses' (henceforth nurses) perceptions of the ethical climate of their work environment, and whether the perceived ethical climate was associated with nurses' self-assessed professional competence, turnover intentions and job satisfaction as central work-related factors. By identifying areas in the ethical climate, which are in association with these work-related factors in the early stage of nurses' career, the aim was to lay a foundation for possible interventions concerning the development of ethical climate since ethical climate can be managed, changed and improved.

\section{Research questions.}

1. What is the ethical climate of their work environment as perceived by nurses? 
2. Is the ethical climate as perceived by nurses associated with their self-assessed professional competence, turnover intentions and job satisfaction?

\section{Study design, instruments and measures}

A descriptive, cross-sectional, correlational research design was used in this study. The used instruments were $\mathrm{HECS}^{22}$ measuring nurses' perception of the ethical climate of the work environment and $\mathrm{NCS}^{41}$ measuring nurses' perceptions of the generic level of their professional competence. Other measures were turnover intentions and job satisfaction. Professional competence, turnover intentions and job satisfaction were treated as work-related factors. Demographic variables were age, sex, previous professional education, work sector, work unit, employment status and type of work shift.

\section{HECS}

HECS measures nurses' perceptions of ethical climate in hospital work environment. ${ }^{6,22}$ The theoretical base of the instrument is on an integrative literature review, concept analysis of ethical climate in healthcare organizations and nurses' experiences in nursing practice and administration. Development of the instrument was guided by the concept of types of organizational climates ${ }^{55}$ and conditions for ethical reflection. ${ }^{56}$

The instrument includes five subscales defining the ethical climate: nurses' perceptions of their relationships with their peers, patients, managers, hospitals and physicians. HECS has been used as a tool to assess the workplace environment, to identify areas in need of improvement and to evaluate the effectiveness of professional practice interventions. Other uses have been to compare perceptions of ethical climate between nurses and physicians as well as different types of care units. ${ }^{7}$ The self-administered questionnaire consists of 26 items to which the respondents indicate the most appropriate alternative on a five-point Likert scale ranging from 1 to 5 (from $1=$ almost never true to $5=$ almost always true). The higher the value of the HECS score, the more positive is the perception of ethical climate. The psychometric properties of the HECS instrument have been proved to be valid and reliable, Cronbach's alpha values estimating internal consistency reliability ranging from 0.88 to 0.95 for the overall HECS and from 0.68 to 0.95 for subscales. $^{6,9,27,36-39}$ In this study, Cronbach's alphas for HECS subscales ranged from 0.71 to 0.91 .

\section{NCS}

The NCS measures self-assessed generic nurse competence in all clinical contexts. ${ }^{45}$ The instrument is based on Benner and colleagues's ${ }^{57,58}$ work. ${ }^{41,59}$ The instrument comprises seven subscales and 73 items. NCS is a self-assessment scale in which responses are given using Visual Analog Scale (VAS 0-100), in which higher VAS score denotes higher generic competence. ${ }^{41}$

In this study, professional competence was treated as a work-related factor and used as a dichotomous variable, using the median VAS score 65 of this study's data as the point to divide nurses into two groups with higher and lower competence levels. The psychometric properties of the NCS instrument have been proved to be valid and reliable, Cronbach's alpha values ranging from 0.72 to $0.96 .{ }^{41,60-64}$ In this study, Cronbach's alphas for NCS subscales ranged from 0.76 to 0.92 .

\section{Other work-related factors}

Other work-related factors were nurses' turnover intention and job satisfaction. Turnover intentions were enquired with two questions as intention to change job or profession. Job satisfaction was enquired with four questions as satisfaction with job orientation, current job, quality of care in the current work unit and with nursing profession. In this study, questions measuring nurses' turnover intentions and job satisfaction 
were retrieved from earlier studies, and each question was treated as an independent variable. All responses were given on a 4-point Likert scale: Turnover intentions $1=$ never/fairly seldom through $4=$ very/fairly often, and job satisfaction $1=$ fully/almost fully disagree through $4=$ fully/almost fully agree.

\section{Sample}

The target group of this national survey was all newly graduated nurses whose registration had taken place between November 2011 and October 2012. Another inclusion criterion was that the length of work experience as a registered nurse did not exceed 12 months. The member registers of the Finnish Nurses' Association and the Union of Health and Social Care Professionals were used to retrieve the eligible participants including their e-mail addresses. A convenience sample using these registers was the most reliable and feasible way to collect national data, in terms of participant accessibility and available financial and time resources. Trade union membership is high in the health and social care sector in Finland with as many as $90 \%$ of employees being members. ${ }^{65}$ The final number of nurses whose e-mail addresses were available was 1050 .

\section{Data collection}

A pilot study was carried out among 13 nurses in different clinical fields to assess the face validity of the questionnaire in the electronic format, including the ethical climate and competence instruments and demographic variables. No revisions were needed. The double-translation procedure of HECS instrument into the Finnish language had been carried out earlier by University of Turku, Finland. The data were collected electronically in November-December in 2012 (http://www.questback.co.uk/). Principal investigator (R.M.) was responsible for the data collection.

An e-mail consisting of a questionnaire on participant demographics, and the HECS and the NCS instruments with a cover letter was sent to a total of 1050 nurses. The cover letter included information about the purpose of the study, reporting of the findings and issues related to research ethics. Two reminder e-mail letters were sent to non-responding participants, first after 2 weeks of the initial data collection and the second a week after the first reminder.

\section{Data analysis}

Statistical software NCSS 9 (Hintze J, Kaysville, UT, USA) was used in data analysis. Frequencies, means, median, percentages, ranges and standard deviations (SDs) summarized the data. General Linear Models (analysis of variance (ANOVA)) were used to estimate associations between the ethical climate of work environment and work-related factors. Multivariate analysis of variance (MANOVA) was used in testing associations between ethical climate types and competence levels. The $p$ values $\leq 0.05$ were considered statistically significant and power-values $\geq 0.800$ (at alpha $=0.05$ ) were regarded strong. IBM Statistical Package for Social Sciences (SPSS) Amos Version 22 (New York, USA) was used to estimate the model fit of HECS instrument in this sample.

\section{Ethical considerations}

The ethical approval was obtained from the Ethics Committee of the University of Turku. Permissions to conduct the study were obtained from the Finnish Nurses Association and the Union of Health and Social Care Professionals, as well as permissions to use the instruments from their copyright holders. Nurses were provided with a full explanation of the purpose of the study and researchers' commitment to research ethics, particularly the confidentiality of the personal data of the participants. For research purposes, the data were 
rendered anonymous, participation was fully voluntary and returning a completed questionnaire was interpreted as consent to participate. ${ }^{66}$

\section{Results}

\section{Participant characteristics}

From the total of 1050 eligible nurses, 318 (30.3\%) returned a completed questionnaire. The mean age of the nurses was 30 years (SD: 8.7 years; median 26 years; range $22-58$ years). The majority of them were women $(\mathrm{n}=285 ; 91 \%)$. Nurses had an average of 9.1 months from their graduation, and an average of 8.0 months of work experience as a registered nurse. About half of the nurses $(n=161 ; 51 \%)$ had previous professional education, mostly from the healthcare sector $(\mathrm{n}=103 ; 32 \%)$. The majority worked in the public healthcare sector $(\mathrm{n}=267 ; 88 \%)$; the private sector employed $35(12 \%)$ of the nurses. ${ }^{67}$ A total of $224(71 \%)$ had a temporary and $90(28 \%)$ nurses had a permanent work status.

\section{Newly graduated nurses' perceptions of the ethical climate of their work environment}

Newly graduated nurses' overall perception of the ethical climate was rather positive (Table 1). Most positive perceptions were in relation to peers and patients. Peer-related matters concerned colleagues' willingness to listen, collegial help, competence of the colleagues and provision of safe care to patients. Patientrelated matters concerned patients' knowledge of their care, nurses' access to patients' records and nurses' possibility to use essential knowledge in caring for patients. Next positive perceptions were in relation to physicians. These matters concerned mutual trust and respect between nurses and physicians, nurses' participation in decision-making and physicians consulting nurses in clinical decisions.

The least positive perceptions of the ethical climate were in relation to hospitals and managers. Hospitalrelated matters concerned the support provided by hospital guidelines, the mission of the hospital, openness of the atmosphere in discussing discrepancies, taking notice of each team members' feelings and values, feelings of freedom to challenge care practices and find creative solutions and nurses' freedom to practice nursing care according to what is right. Manager-related matters concerned manager's help and support for nurses in difficult decision-making situations, manager's willingness to listen and nurses' trust and respect towards the managers. Confirmatory factor analysis (CFA) was used to examine how consistent our sample data were with HECS instrument. According to the statistical tests, the model fit was moderate: root mean square error of approximation $($ RMSEA) $=0.093$, normed fit index $($ NFI $)=0.735$ and Minimum Discrepancy/Degrees of Freedom $(\mathrm{CMIN} / \mathrm{DF})=3.305$.

\section{Professional competence and other work-related factors associated with ethical climate}

The second research question focused on the associations between perceptions of ethical climate and workrelated factors assigned as nurses' (a) self-assessed professional competence, (b) turnover intentions in terms of changing job or profession and (c) job satisfaction in terms of job orientation, current job, quality of care in the current work unit and satisfaction with nursing profession.

The correlation between nurses' professional competence and their perceptions of the ethical climate was positive but moderate $(\mathrm{r}=0.307, \mathrm{p}<0.001)$ (Table 2$)$. In terms of ethical climate, the strongest, significant positive correlations with competence were related to physicians, hospitals and managers. Weaker, but still significant correlations, were related to peers and patients. 
Table I. Mean and SD of nurses' perceptions of ethical climate of their work environment $(n=318)$.

\begin{tabular}{|c|c|c|}
\hline HECS $\left(\mathrm{Olson}^{22}\right)$ & Mean & SD \\
\hline \multicolumn{3}{|l|}{ Sum variables and items } \\
\hline Peers & 4.33 & 0.54 \\
\hline My peers listen to my concerns about patient care & 4.16 & 0.75 \\
\hline My peers help me with difficult patient care issues/problems & 4.37 & 0.71 \\
\hline I work with competent colleagues & 4.38 & 0.67 \\
\hline Safe patient care is given on my unit & 4.43 & 0.58 \\
\hline Patients & 4. 10 & 0.52 \\
\hline Patients know what to expect from their care & 3.63 & 0.77 \\
\hline Nurses have access to the information necessary to solve a patient care issue/problem & 4.24 & 0.72 \\
\hline Nurses use the information necessary to solve a patient care issue/problem & 4.32 & 0.65 \\
\hline The patient's wishes are respected & 4.22 & 0.71 \\
\hline Physicians & 3.74 & 0.58 \\
\hline Nurses and physicians trust one another & 3.98 & 0.69 \\
\hline Physicians ask nurses for their opinions about treatment decisions & 3.47 & 0.93 \\
\hline I participate in treatment decisions for my patients & 3.68 & 0.91 \\
\hline $\begin{array}{l}\text { Nurses and physicians here respect each others' opinions, even when they disagree about what is best } \\
\text { for patients }\end{array}$ & 3.71 & 0.85 \\
\hline Nurses and physicians respect one another & 3.93 & 0.77 \\
\hline Nurses are supported and respected in this hospital & 3.68 & 0.86 \\
\hline Hospitals & 3.54 & 0.64 \\
\hline Hospital policies help me with difficult patient care issues/problems & 3.37 & 0.93 \\
\hline A clear sense of the hospital's mission is shared with nurses & 3.67 & 0.80 \\
\hline $\begin{array}{l}\text { The feelings and values of all parties involved in a patient care issue/problem are taken into account } \\
\text { when choosing a course of actions }\end{array}$ & 3.48 & 0.84 \\
\hline Conflict is openly dealt with, not avoided & 3.27 & 1.00 \\
\hline There is a sense of questioning, learning and seeking creative responses to patient care problems & 3.56 & 0.91 \\
\hline I am able to practice nursing in my unit as I believe it should be practiced & 3.88 & 0.83 \\
\hline Managers & 3.50 & 0.91 \\
\hline When I am unable to decide what is right or wrong in a patient care situation, my manager helps me & 3.37 & I.II \\
\hline My manager supports me in my decisions about patient care & 3.31 & 1.15 \\
\hline My manager listens to me talk about patient care issues/problems & 3.61 & 1.10 \\
\hline My manager is someone I can trust & 3.77 & I.0I \\
\hline $\begin{array}{l}\text { When my peers are unable to decide what's right or wrong in a particular patient care situation, I have } \\
\text { observed that my manager helps them }\end{array}$ & 3.20 & 1.16 \\
\hline My manager is someone I respect & 3.79 & 0.98 \\
\hline Overall score & 3.84 & 0.45 \\
\hline
\end{tabular}

SD: standard deviation; HECS: Hospital Ethical Climate Survey.

There was a statistically significant $(\mathrm{p}<0.001)$ difference between the groups in favour of nurses at the higher competence level related to the overall HECS mean. The differences were significant also in relation to each HECS subscale (Table 3).

Other statistically significant associations were found between newly graduated nurses' perceptions of the ethical climate and their job satisfaction, and turnover intentions. Main effects of ANOVA indicated that (a) nurses at a higher competence level, (b) nurses who were never/very seldom planning to change their jobs, (c) nurses who were satisfied with their job orientation and (d) nurses who were satisfied with the quality of care in their work unit had significantly more positive perceptions of the ethical climate. Power statistic shows that the associations were strong except in relation to job orientation (Table 4). 
Table 2. Correlation between ethical climate and professional competence $(n=297)$.

\begin{tabular}{lrr}
\hline HECS vs NCS & Pearson's $r$ & P value \\
\hline Peers & $r=0.170$ & 0.003 \\
Patients & $r=0.168$ & 0.004 \\
Managers & $r=0.199$ & $<0.001$ \\
Hospitals & $r=0.234$ & $<0.001$ \\
Physicians & $r=0.311$ & $<0.001$ \\
All & $r=0.307$ & $<0.001$ \\
\hline
\end{tabular}

NCS: Nurse Competence Scale; HECS: Hospital Ethical Climate Survey.

Table 3. Comparison of perceptions of ethical climate and professional competence (multivariate analysis of variance, $\mathrm{n}=297)$.

\begin{tabular}{lccrc}
\hline Instrument HECS & Higher competence VAS, mean $>65$ & Lower competence VAS, mean $\leq 65$ & F ratio & P value \\
\hline Peers & 4.41 & 4.27 & 5.50 & 0.020 \\
Patients & 4.19 & 4.00 & 9.10 & $0.003^{*}$ \\
Managers & 3.63 & 3.35 & 7.16 & $0.008^{*}$ \\
Hospitals & 3.65 & 3.42 & 9.86 & $0.002^{*}$ \\
Physicians & 3.90 & 3.59 & 22.85 & $<0.00 I^{*}$ \\
HECS/all & 3.95 & 3.73 & 20.48 & $<.00 I^{*}$ \\
\hline
\end{tabular}

VAS: Visual Analog Scale; HECS: Hospital Ethical Climate Survey.

$*$ Significant at level $\mathrm{p} \leq 0.0083$ (in multiple comparison, significance level 0.05 equals $0.05 / 6=.0083$ ).

Two-way interaction effects indicated that nurses who were not satisfied with the quality of care perceived the ethical climate equally positively regardless of their level of professional competence (both means: 3.48). Instead, nurses who were satisfied with the quality of care had different perceptions of the ethical climate: nurses at the higher competence level perceived the ethical climate more positively (mean: 3.98) than nurses at the lower competence level (mean: 3.71). Moreover, nurses who were satisfied with their job orientation and with the quality of care perceived the ethical climate more positively (mean: 3.93) than (a) nurses who were not satisfied with their job orientation, but who were satisfied with the quality of care (mean: 3.76); (b) nurses who were not satisfied with their job orientation or with the quality of care (mean: 3.53) and (c) nurses who were satisfied with their job orientation, but not satisfied with the quality of care (mean: 3.42). Power statistic shows that the associations were strong particularly in relation to changing job and satisfaction with quality of care. (Table 5).

\section{Discussion}

This study examined newly graduated nurses' perception of the ethical climate of their work environment and its associations with professional competence, turnover intentions and job satisfaction as central workrelated factors. Although associations between ethical climate of nurses' work environment have previously been studied with several work-related factors, to our knowledge, this is the first time when ethical climate's relationship with professional competence has been in focus in nursing context. The main findings of our study indicated that nurses' perception of the ethical climate was positive. Furthermore, positive perception of the climate was associated with a higher professional competence, lower turnover intentions and higher job satisfaction. 
Table 4. Significant main effects between nurses' perceptions of ethical climate and work-related factors $(\mathrm{n}=298)$ (analysis of variance).

\begin{tabular}{|c|c|c|c|c|c|c|}
\hline \multicolumn{7}{|l|}{ Main effects } \\
\hline Work-related factors & Response format & $\begin{array}{l}\text { Adjusted } \\
\text { mean/HECS }\end{array}$ & $\begin{array}{l}\text { Sum of } \\
\text { squares }\end{array}$ & $\mathrm{F}$ ratio & $P$ value & Power $=0.05$ \\
\hline Professional competence & $\begin{array}{l}V A S>65 \\
V A S \leq 65\end{array}$ & $\begin{array}{l}3.78 \\
3.58\end{array}$ & 2.878 & 20.30 & $<0.001 *$ & 0.994 \\
\hline \multicolumn{7}{|l|}{ Job satisfaction } \\
\hline Satisfied with orientation & $\begin{array}{l}\text { Agree } \\
\text { Disagree }\end{array}$ & $\begin{array}{l}3.73 \\
3.62\end{array}$ & 0.733 & 5.17 & $0.002^{*}$ & 0.620 \\
\hline Satisfied with the quality of care & $\begin{array}{l}\text { Agree } \\
\text { Disagree }\end{array}$ & $\begin{array}{l}3.85 \\
3.51\end{array}$ & 4.512 & 31.87 & $<0.00 I^{*}$ & 0.910 \\
\hline \multicolumn{7}{|l|}{ Turnover intentions } \\
\hline Planning to change job & $\begin{array}{l}\text { Never/fairly seldom } \\
\text { Very/fairly seldom }\end{array}$ & $\begin{array}{l}3.79 \\
3.56\end{array}$ & 3.256 & 22.97 & $<0.001 *$ & 0.998 \\
\hline
\end{tabular}

VAS: Visual Analog Scale; HECS: Hospital Ethical Climate Survey.

*Significant at level $\mathrm{p} \leq 0.05$.

Table 5. Significant main effects and two-way interactions between nurses' perceptions of ethical climate and workrelated factors $(n=298)$ (analysis of variance).

Main effects and two-way interactions

\begin{tabular}{|c|c|c|c|c|c|c|}
\hline Work-related factors & Response format & $\begin{array}{c}\text { Adjusted } \\
\text { mean/HECS }\end{array}$ & Sum of squares & $\mathrm{F}$ ratio & $P$ value & Power \\
\hline \multirow[t]{2}{*}{ Professional competence } & VAS > 65 & 3.73 & 0.744 & 5.35 & $0.02 I^{*}$ & 0.635 \\
\hline & VAS $\leq 65$ & 3.59 & & & & \\
\hline \multirow[t]{2}{*}{ Planning to change job } & Never/fairly seldom & 3.80 & 2.856 & 20.56 & $<0.001 *$ & 0.995 \\
\hline & Very/fairly seldom & 3.53 & & & & \\
\hline \multirow{2}{*}{$\begin{array}{l}\text { Satisfied with the quality of } \\
\text { Care }\end{array}$} & Agree & 3.84 & 4.910 & 35.34 & $<0.001 *$ & 0.910 \\
\hline & Disagree & 3.48 & & & & \\
\hline Professional competence & VAS > 65 - Agree & 3.98 & 0.616 & 4.44 & $0.036 *$ & 0.555 \\
\hline \multirow{3}{*}{$\begin{array}{l}\text { Satisfied with the quality of } \\
\text { care }\end{array}$} & VAS $\leq 65$ - Agree & 3.71 & & & & \\
\hline & VAS > 65 - Disagree & 3.48 & & & & \\
\hline & VAS $\leq 65-$ Disagree & 3.48 & & & & \\
\hline \multirow{4}{*}{$\begin{array}{l}\text { Satisfied with orientation } \\
\text { Satisfied with the quality of } \\
\text { care }\end{array}$} & Agree - Agree & 3.93 & 0.726 & 5.23 & $0.023^{*}$ & 0.625 \\
\hline & Disagree - Agree & 3.76 & & & & \\
\hline & Disagree - Disagree & 3.53 & & & & \\
\hline & Agree - Disagree & 3.42 & & & & \\
\hline
\end{tabular}

VAS: Visual Analog Scale; HECS: Hospital Ethical Climate Survey.

*Significant at level $\mathrm{p} \leq 0.05$.

Nurses' positive perception of the ethical climate is mainly in accordance with earlier studies. ${ }^{27,38}$ Positive perceptions were particularly related to peers and patients, but also to physicians in enhancing ethical climates to develop. ${ }^{35,37}$ Findings reflect nurses' positive view of their peers in terms of their willingness to listen, help and provide safe care to the patients as competent colleagues. In relation to patients, knowledge needed in patient care and adequate addressing of patients' wishes were 
acknowledged. Positive perceptions of physicians implied that novice nurses felt respected, listened to and consulted by physicians in ethical and clinical issues. Earlier studies have indicated that due to professional hierarchies, nurses have felt themselves silenced by physicians in ethical and clinical decision-making situations, ${ }^{5,40,68}$ and that working as a team and sharing responsibility contribute to the development of positive ethical climates. ${ }^{31,34}$

Managers' contribution to the ethical climate was perceived less positively in this study. This is contrary to some earlier studies. ${ }^{27,35,37}$ This suggests that managers' support in decision-making, willingness to listen nurses and nurses' trust and respect towards their managers is somewhat lacking. Keeping in mind that nurses' overall perception of the ethical climate was positive, this is, however, a worrying finding, unless it refers somehow to nurses' inexperience and general uncertainty to perceive and to handle ethical issues in clinical practice. ${ }^{15,16}$ Managers have a crucial impact on creating and maintaining positive ethical climates. Their leadership style and support to nurses correlate with the existing ethical climate of their work environments and, consequently, how ethical issues are dealt with for the good of the patient. ${ }^{30-33}$ Positive ethical climate, institutional support in dealing with ethical issues and job satisfaction protect nurses from their turnover intentions or intentions to leave the profession, ${ }^{39}$ and therefore, managers' role is of a paramount importance in today's healthcare systems struggling with nurse turnover issues. ${ }^{69}$ This is particularly pertinent in Finland since Finnish nurses have indicated in European comparison fairly high willingness to change their job or leave the profession in the near future. ${ }^{11,12}$

As was the case with managers, also hospitals' contribution to enhancing positive ethical climates was perceived less positively in this study. This suggests that both managers and hospital administrations should have better understanding of their roles as contributors to positive ethical climate and its development. Various studies have indicated a significantly strong relationship, on one hand, between positive ethical climate and nurses' morally courageous action in advocating for their patients ${ }^{33}$ and, on the other hand, between negative ethical climate and nurses' moral distress, and how high level of moral distress is associated with nurses' turnover intentions and leaving the profession. ${ }^{35,37}$ Ethical climate should not be made yet another factor to enhance turnover tendency to continue. However, Olson ${ }^{22}$ points out, referring to her instrument, that in ethical climate, various factors interact and the subscales of her instrument are highly inter-correlated and should therefore not be considered fully independently.

The associations between ethical climate and newly graduated nurses' professional competence, turnover intentions and job satisfaction need further discussion. Although nurses' overall competence was at good level both at higher and lower competence levels, ${ }^{47}$ nurses at the higher level perceived the ethical climate more positively than nurses at the lower level. Perhaps more competent nurses have passed the task-oriented performance phase typical of newly graduated nurses and are therefore able to look at their work environment more comprehensively and confidently as a combination of various contributing factors. Belief in one's own competence increases the feeling of self-confidence and consequently positive attitudes towards surrounding circumstances in general. ${ }^{15,70}$

Strong associations between positive view of the ethical climate, own professional competence, quality of care and nursing as a job seemed to be important interacting factors in novice nurses' work environment. Earlier research has shown ethical climate's association with various work-related factors. ${ }^{9,13,25,27,35-38}$ This study supports the hypothesis that ethical climate is also associated with newly graduated nurses' professional competence, a pivotal element in provision of quality care.

\section{Strengths and limitations}

Both instruments used in this study are scientifically developed and their validity has been proved in a number of studies (see 'Study design, instruments and measures' section). Our primary choice to use 
HECS instrument was justified, because to our knowledge, it is the only instrument specifically developed to measure nurses' perceptions of ethical climate. However, CFA showed that the Model Fit of HECS is moderate in these data indicating that there may be a need for minor revision of some items. HECS is just one way to measure ethical climate; there are also other ways and perspectives to approach it, and also instruments available which could have been applied in nursing context ${ }^{18}$ to extend the understanding of ethical climates and its association with work-related factors. Moreover, the subjectivity of self-assessments should always be taken into account in interpretation of the results. Other assessment methods are suggested to be used in conjunction with self-assessments. ${ }^{71}$ There exist validated instruments to measure both turnover intentions and job satisfaction. However, this was justified on the basis that completing several lengthy questionnaires may have already been experienced as time consuming, a known factor causing non-responsiveness. ${ }^{72}$ Fairly modest response rate, although a common difficulty associated with survey studies, ${ }^{73}$ may somewhat jeopardizes the validity of research findings and the accuracy of measures of association by introducing non-response or participation bias and increasing the risk of Type II error. ${ }^{66}$ Furthermore, generalization of the findings remains limited because the study was carried out in one country and nursing culture. However, nurses in this study represented a national sample of registered newly graduated nurses.

\section{Conclusion and further research}

Newly graduated nurses perceived the ethical climate of their work environment positive. Positive perceptions were associated with higher professional competence, higher job satisfaction and lower turnover intentions. The most positive perceptions were related to peers, patients and physicians, and the less positive to managers and hospital. Strong interaction between ethical climate, nurses' intention to change job, satisfaction with quality of care and professional competence should be recognized. Nursing management responsible for and having the power to implement changes should fully understand their contribution to ethical leadership, as well as the multidimensional nature of nurses' work environment and the interaction between work-related factors in planning developmental measures.

Future research should focus on issues in nurse managers' ethical leadership in creating positive ethical work environments. There is also a need for detailed knowledge of newly graduated nurses' views of factors which act as enhancers or barriers to positive ethical climates to develop. Interventions, continuing education courses and discussions designed to promote positive ethical climates should be developed to managers, nurses and multi-professional teams.

\section{Acknowledgements}

Study conception and design: R.M., O.N., H.L-K.; data collection: R.M.; data analysis: O.N., H.I.; drafting of manuscript: O.N., R.M.; critical revisions of manuscript for important intellectual content: R.M., H.L-K.; statistical expertise: O.N., H.I.; obtaining funding: R.M.; administrative, technical or material support: R.M., H.L-K.; supervision: R.M., H.L-K.

\section{Conflict of interest}

None declared.

\section{Funding}

This work was supported by The Finnish Work Environment Fund and Hospital District of Helsinki and Uusimaa, Finland. 


\section{References}

1. Gastmans C. Editorial comment. Nurs Ethics 2001; 8: 94-95.

2. McGilles Hall L and Doran D. Nurse staffing, care delivery model, and patient care quality. J Care Qual 2008; 19 : 2-33.

3. Rodney P, Doane G, Storch J, et al. Toward a safer moral climate. Can Nurse 2006; 102: 24-27.

4. Hartrick Doane G. Am I still ethical? The socially-mediated process of nurses' moral identity. Nurs Ethics 2002; 9: 623-635.

5. Varcoe C, Doane G, Pauly B, et al. Ethical practice in nursing: working the in-betweens. J Adv Nurs 2004; 45: 316-325.

6. Olson L. Hospital nurses' perceptions of the ethical climate of their work environment. Image: J Nurs Sch 1998; 30 : 345-349.

7. Olson L. Ethical climate as the context for nurse retention. Chart 2002; 99: 3-7.

8. Bell S. Ethical climate in managed care organizations. Nurs Admin Q 2003; 27: 133-139.

9. Hart S. Hospital ethical climates and registered nurses' turnover intensions. J Nurs Sch 2005; 37: 173-177.

10. Wlody G. Nursing management and organizational ethics in the intensive care unit. Crit Care Med 2007; 35(Suppl.): 29-35.

11. Aiken L, Sermeus W, Van den Heede K, et al. Patient safety, satisfaction, and quality of hospital care: cross sectional surveys of nurses and patients in 12 countries in Europe and the United States. BMJ 2012; 344: e1717.

12. Flinkman M, Leino-Kilpi H and Salanterä S. Nurses' intention to leave the profession: integrative review. Int $J$ Nurs Stud 2008; 45: 727-739.

13. Corley M, Minick P, Elswick R, et al. Nurse moral distress and ethical work environment. Nurs Ethics 2005; 12 : 381-390.

14. Clark T and Holmes S. Fit for practice? An exploration of the development of newly qualified nurses using focus groups. Int J Nurs Stud 2007; 44: 1210-1220.

15. Duchscher J. A process of becoming: the stages of new nursing graduate professional role transition. J Contin Educ Nurs 2008; 39: 441-450.

16. Wangensteen S, Johansson I and Nordström G. The first year as a graduate nurse - an experience of growth and development. J Clin Nurs 2008; 17: 1877-1885.

17. Heikkinen A and Leino-Kilpi H. Eettiset ohjeet - näkökulma hoitotyön etiikan koulutukseen [Codes of ethics - a perspective on ethics education in nursing]. In: Salminen L and Hupli M (eds) Working as a health care educator in the 21st century, part I (Department of Nursing Science, research reports A. 44/2004). Turku: University of Turku, 2004, pp. 58-65. (in Finnish).

18. Victor B and Cullen J. The organisational bases of ethical work climate. Admin Sci Q 1988; 33: 101-125.

19. Martin K and Cullen J. Continuities and extensions of ethical climate theory: a meta-analytic review. J Business Ethics 2006; 69: 175-194.

20. Leino-Kilpi H, Suominen T, Mäkelä M, et al. Organizational ethics in Finnish intensive care units: staff perceptions. Nurs Ethics 2002; 9: 126-136.

21. Schluter J, Winch S, Holzhauser K, et al. Nurses' moral sensitivity and hospital ethical climate: a literature review. Nurs Ethics 2008; 15: 304-321.

22. Olson L. Ethical climate in health care organizations. Int Nurs Rev 1995; 42: 85-95.

23. White J and Wallace D. The integrity audit. St Paul, MN: Center for Ethics, Responsibilities, and Values, College of St. Catherine, 1988.

24. McDaniel C. Development and psychometric properties of the ethics environment questionnaire. Med Care 1997; 35: 901-914.

25. Hui E. A survey of ethics climate of Hong Kong public hospitals. Clin Ethics 2008; 3: 132-140.

26. Filipova A. Licensed nurses' perceptions of ethical climates in skilled nursing facilities. Nurs Ethics 2009; 16 : 574-578. 
27. Bahcecik N and Oztürk H. The Hospital Ethical Climate Survey in Turkey. JONAS Healthc Law Ethics Regul 2003; 5: 94-95.

28. Joseph J and Deshpande S. The impact of ethical climate on job satisfaction of nurses. Health Care Manag Rev 1997; 22: 76-81.

29. Goldman A and Tabak N. Perceptions of ethical climate and its relationship to nurses' demographic characteristics and job satisfaction. Nurs Ethics 2010; 17: 233-246.

30. Huang C-C, You C-S and Tsai M-T. A multidimensional analysis of ethical climate, job satisfaction, organizational commitment, and organizational citizenship behaviours. Nurs Ethics 2012; 19: 513-529.

31. Rathert $\mathrm{C}$ and Fleming D. Hospital ethical climate and teamwork in acute care: the moderating role of leaders. Health Care Manag Rev 2008; 33: 323-331.

32. Storch J, Rodney P, Pauly B, et al. Enhancing ethical climates in nursing work environments. Can Nurse 2009; 105 : $20-25$.

33. Storch J, Rodney P, Varcoe C, et al. Leadership for ethical policy and practice (LEPP): participatory action project. Nurs Leadership 2009; 22: 68-80.

34. Silén M, Kjellström S, Christensson L, et al. What actions promote a positive ethical climate? A critical incident study of nurses' perceptions. Nurs Ethics 2012; 19: 501-512.

35. Pauly B, Varcoe C, Storch J, et al. Registered nurses' perceptions of moral distress and ethical climate. Nurs Ethics 2009; 16: 561-573.

36. Lützén K, Blo T, Ewalds-Kvist B, et al. Moral stress, moral climate and moral sensitivity among psychiatric professionals. Nurs Ethics 2010; 17: 213-224.

37. Silén M, Svantesson M, Kjellström S, et al. Moral distress and ethical climate in a Swedish nursing context: perceptions and instrument usability. J Clin Nurs 2011; 20: 3483-3493.

38. Hwang J-I and Park H-A. Nurses' perception of ethical climate, medical error experience and intent to leave. Nurs Ethics 2014; 21: 28-42.

39. Ulrich $\mathrm{C}$, O'Donnell $\mathrm{P}$, Taylor $\mathrm{C}$, et al. Ethical climate, ethics stress and job satisfaction of nurses and social workers in the United States. Soc Sci Med 2007; 65: 1708-1719.

40. Malloy D, Hadjistavropoulos T, McCarthy E, et al. Culture and organizational climate: nurses' insights into their relationship with physicians. Nurs Ethics 2009; 16: 719-733.

41. Meretoja R, Isoaho $\mathrm{H}$ and Leino-Kilpi $\mathrm{H}$. Nurse Competence Scale: development and psychometric testing. $J A d v$ Nurs 2004; 47: 124-133.

42. Cowin L, Hengsberger-Sims C, Eagar S, et al. Competency measurements: testing convergent validity for two measures. J Adv Nurs 2008; 64: 272-277.

43. Price J. The development of a causal model of voluntary turnover. In: Griffeth R and Hom P (eds) Innovative theory and empirical research on employee turnover. Greenwich, CT: Information Age Publishing, 2004, pp. 3-32.

44. Morrell K. Towards a typology of nursing turnover: the role of shocks in nurses' decision to leave. $J$ Adv Nurs 2005; 49: 315-322.

45. Krausz M, Koslowsky M, Shalom N, et al. Predictors of intentions to leave the ward, the hospital, and the nursing profession: a longitudinal study. J Organiz Behav 1995; 16: 277-288.

46. Spector P. Job satisfaction. Thousand Oaks, CA: Sage, 1997.

47. Wangensteen S, Johansson I, Björkström M, et al. Newly graduated nurses' perception of competence and possible predictors: a cross-sectional survey. J Prof Nurs 2012; 28: 170-181.

48. Lima S, Newall F, Kinney S, et al. How competent are they? Graduate nurses self-assessment of competence at the start of their careers. Collegian. Epub ahead of print 4 October 2013. DOI: 10.1016/j.colegn.2013.09. 001 .

49. Marsburn D. Clinical competence, satisfaction, and intent to stay in new nurses. Doctoral dissertation, East Carolina University, Greenville, NC, 2007. 
50. Hasselhorn H, Conway P, Widerszal-Bazyl M, et al. Contribution of job strain to nurses' consideration of leaving the profession - results from a longitudinal European Nurses' Early Exit Study. Scand J Work Environ Health Suppl 2008; 6: 75-82.

51. Ulrich B, Krozek C, Early S, et al. Improving retention, confidence, and competence of graduate nurses: results from a 10-year longitudinal database. Nurs Econ 2010; 28: 363-375.

52. Walker A and Campbell K. Work readiness of graduate nurses and the impact on job satisfaction, work engagement and intention to remain. Nurs Educ Today 2013; 33: 1490-1495.

53. Laschinger $\mathrm{H}$. Job and career satisfaction and turnover intentions of newly graduated nurses. J Nurs Manag 2012; 20: 472-484.

54. Estryn-Behar M, Van der Heijden B, Fry C, et al. Longitudinal analysis of personal and work-related factors associated with turnover among nurses. Nurs Res 2010; 59: 166-177.

55. Schneider B. The climate for service: an application of the climate construct. In: Schneider B (ed.) Organizational climate and culture. San Francisco, CA: Jossey-Bass, 1990, pp. 383-412.

56. Brown M. Working ethics. San Francisco, CA: Jossey-Bass, 1990.

57. Benner P. From novice to expert: excellence and power in clinical nursing practice. Menlo Park, CA: AddisonWesley, 1984.

58. Benner P, Tanner C and Chesla C. Expertise in nursing practice: caring, clinical judgment, and ethics. New York: Springer, 1996.

59. Meretoja R and Leino-Kilpi H. Instruments for evaluating nurse competence. $J$ Nurs Admin 2001; 31: 346-352.

60. Salonen A, Kaunonen M, Meretoja R, et al. Competence profiles of recently registered nurses working in intensive and emergency settings. $J$ Nurs Manag 2007; 15: 792-800.

61. Bahreini M, Moattari M, Ahmadi F, et al. Comparison of head nurses and practicing nurses in nurse competence assessment. Iran J Nurs Midwifery Res 2011; 16: 227-234.

62. Hamström N, Kankkunen P, Suominen T, et al. Short hospital stays and new demands for nurse competencies. Int $J$ Nurs Prac 2012; 12: 501-508.

63. O'Leary J. Comparison of self-assessed competence and experience among critical care nurses. J Nurs Manag 2012; 20: 607-614.

64. Kajander-Unkuri S, Meretoja R, Katajisto J, et al. Self-assessed level of competence of graduating students and factors related to it. Nurs Educ Today 2014; 34: 795-801.

65. http://www.tehy.fi/en/about-us/tehy-membership/ (accessed 24 June 2014).

66. Burns $\mathrm{N}$ and Grove $\mathrm{S}$. The practice of nursing research: appraisal, synthesis, and generation of evidence. 6th ed. St. Louis, MO: Saunders Elsevier, Inc., 2009.

67. Health Care in Finland, http://www.stm.fi/c/document_library/get_file?folderId=6511570\&name=DLFE-26813. pdf (2013, accessed 24 June 2014).

68. Newton L, Storch J, Makaroff K, et al. 'Stop the noise!' From voice to silence. Nurs Leadership 2012; 25: 90-104.

69. Shirley M. Ethical climate in nursing practice. The leader's role. JONAS Healthc Law Ethics Regul 2005; 7 : $59-67$.

70. Andersson $\mathrm{P}$ and Edberg A-K. The transition from rookie to genuine nurse: narratives from Swedish nurses 1 year after graduation. J Contin Educ Nurs 2010; 41: 186-192.

71. National Education Framework for Cancer Nursing (EdCaN). Competency assessment in nursing: a summary of literature published since 2000. Prepared on behalf of EdCaN by Alison Evans Consulting, April 2008, http:// www.edcan.org/pdf/EdCancompetenciesliteraturereviewFINAL.pdf

72. Barribal L and While A. Exploring variables underlying non-response in a survey of nurses and nurses' aides in practice. J Adv Nurs 1999; 29: 894-904.

73. O'Rourke W. The importance of an adequate survey response rate and ways to improve it. Am J Health Stud 1999; 15: 107-109. 